\title{
Н.П. Бобкова
}

\section{СПЕКТР ОБСУЖДАЕМЫХ ПОЛИТИЧЕСКИХ ТЕМ НА СТРАНИЦАХ ПЕЧАТНЫХ ИЗДАНИЙ ТОМСКОЙ ОБЛАСТИ 1990-1997 гГ.}

\begin{abstract}
Актуальность темы исследования обусловливается возрастающей ролью оппозиционной политической пропаганды и проявлением интереса к изучению проблемы в историческом аспекте. Предметом научной работы являются политические темы на страницах печатных изданий Томской области 1990-1997 гг. Основными методами исследования выступают принцип историзма и контент-анализ прессы. Результатом работы стал анализ региональных печатных изданий, который позволил автору сделать вывод о том, что местные издания отражали политическую ситуацию в стране и области, имели свой взгляд на происходящие события.

Ключевые слова: печатные издания; политические публикации; политические партии; политические деятели; политические позиции.
\end{abstract}

Первые годы проводимых сначала в СССР, а затем в РФ экономических (рыночных) реформ сопровождались резким снижением уровня жизни населения и глубоким административным и политическим кризисом. Все эти явления и процессы были актуальны для редакторских коллективов как центральной, так и региональной прессы. Ввиду обширности опубликованного печатными средствами массовой информации (СМИ) материала тех лет, является целесообразным проанализировать его всесторонне по регионам. Целью данного исследования является освещение ряда политических проблем начала 1990-х гг. на основе материалов печатных СМИ Томской области.

Так, независимое информагентство «Сибирь» и его издание «Народная воля» 1990 г. города Томска опубликовало статьи с громкоговорящими заголовками: «Президента и правительство - в отставку!», «Роковая ошибка Ленина», «Правда о КПСС», «Детектив». Автор статьи «Кризис власти - кризис экономики» на первой полосе пытался убедить читателей в несостоятельности политики реформ: «С момента прихода к власти Горбачева ни одна программа под его руководством не завершилась успехом».

Автором были перечислены многочисленные провалы в экономике и политике, такие как: дискредитация госприемкой наших товаров на внутреннем и зарубежном рынках; лихорадка промышленного производства; хаос в снабжении из-за децентрализации; инфляция; грабежи, насилие, убийства, национализм, преступность. Далее автор задает вопрос: «А задумывались ли Вы, уважаемый читатель, почему это рукоплещут политике Горбачева руководители США, Англии, Франции? Может, они радуются нашим успехам?». Здесь же приводится ответ: «Отнюдь! Они видят, что действия нашего руководства разрушают наше хозяйство, рушат наш Союз и подрывают обороноспособность нашей страны. Все надежды народа были обращены на народных депутатов. В предвыборных речах они били себя в грудь, обещая защищать интересы народа. И поначалу все шло хорошо. Приняты законы о пенсиях, о повышении заработной платы. Но вот рос- сийскими депутатами во главе с Ельциным, а затем и союзными принимается программа перехода к рыночной экономике...». В итоге автор делает вывод о том, что «пора кончать это безумие... Такая власть нам не нужна!!!» [1. Л. 1].

Содержание статьи указывает на наличие социальных и политических противоречий в советском обществе. На то, что эти проблемы зародились намного раньше, указывают рассуждения на страницах местной прессы о ходе избирательной кампании 1989 г.

Корреспондент еженедельной газеты Томского областного совета народных депутатов в № 1 от 24 мая 1990 г. «Народная трибуна» («НТ») в статье «Новые люди в парламенте» вспоминает кампанию «Выборы-89», которая, по словам автора, протекала очень остро. Эта острота объясняется, «во-первых, активнейшим противостоянием двух сил: партийная, старая советская и административная структуры, привыкшие к беспредельной власти, с одной стороны, и молодая демократическая поросль, осмелившаяся оспаривать эту власть, с другой стороны. И чем сильнее было давление аппарата, тем активнее и более массовым было сопротивление демократических сил. Во-вторых, число кандидатов и депутатских мест было малым, а население лучше информировано о претендентах, которые шли по территориальным округам. В-третьих, подобные выборы (в условиях разрешенной гласности и нескольких фамилий в бюллетене) проводились впервые» [2. Л. 2].

Далее в этом же номере «Народной трибуны» корреспондент «НТ» поздравляет председателя областного Совета В.М. Кресса с избранием на «столь ответственный пост». Но прежде интервьюер напомнил о том, что не всегда выдвижение В.М. Кресса оказывалось удачным: «Говорят даже, что ваша жена запрещала вам участвовать в подобного рода мероприятиях, поскольку вы становитесь “штатным кандидатом”. Но вот, наконец, и вы, и ваша семья, и сторонники могут испытать чувство облегчения - в острой борьбе вам отдано предпочтение» [Там же].

Стоит отметить, что простым людям, избирателям трудно было сориентироваться в новых политических 
условиях, что демонстрируют обзоры писем читателей 1990 г. в адрес редакции местных Томских газет «Красное знамя» и «Народная трибуна». В частности, одно из таких посланий содержит размышления женщины, которая сетует: «Дорогая редакция! <..> трудно мы стали жить. Озлобленность, непорядочность людскую показал митинг 25 февраля в Томске. Когда мы выбирали депутатов, я голосовала за Сулакшина. Те, кто за него агитировал, внушили мне, что это тот человек, который будет жить для людей. Но на митинге он мне не понравился. Какой-то самодовольный человек, которому до простых людей дела нет, одна забота протащить к власти своих» [3. Л. 102].

И еще похожее мнение читателя: «Уважаемая редакция газеты «Красное знамя»! < ..> когда прочел в № 25 газеты «Красное знамя» от 30.01 .1990 г. статью нашего народного депутата СССР С.С. Сулакшина разочаровался. Кроме разговоров о 6-й статье Конституции СССР, об ответственности некоторых руководителей ЦК КПСС. Недавно я прочел беседы с народным депутатом СССР Н.П. Белоусом и был очень доволен его глубокими мыслями о наших делах, проникнутыми заботой о людях. Мне жаль, что я голосовал на выбоpax не за Белоуса Н.П., а за Сулакшина С.С.» [Там же. Л. 103].

Однако выборы кандидатов в депутаты - это было ещё не самым сложным для советского избирателя, а вот явление многопартийности оказалось куда более непривычным и непонятным. В однопартийной системе советского государства к 1990 г. оформляются многочисленные общественно-политические движения и организации.

«Республика» - под таким названием вышел в 1990 г. нулевой номер газеты Томского отделения республиканской партии России. Например, в этом номере были статьи с заголовками, говорящими сами за себя: В. Шестаковский «Надо помочь Горбачеву достойно уйти в историю»; В. Лысенко «Коммунистическая идеология стала главной причиной многочисленных бед и трагедий российского народа»; И. Чубайс «Я против всеобщей любви всех со всеми, от этого можно заболеть политическим СПИДом»; С. Сулакшин «Надо поддерживать президента»; «Социологические данные», «Для деловых людей республики», «Застрахован ли Борис Ельцин?», «Егор Лигачев дает показания» [4. Л. 3].

Демократический настрой постепенно приобретал все большую популярность среди политиков. Так, например, Б.К. Шайдуллин, депутат областного совета, член координационного совета Томского отделения Республиканской партии России (РПР), в статье «Мы за предпринимателя» высказался за скорейший переход к рыночной экономике: «Тема социальной защиты малообеспеченных слоев населения при переходе к рынку становится неким объектом декларативных спекуляций: “Защитим народ от рынка! Частная собственность усилит нищету больных и престарелых!” Особенно в этом усердствует КПСС, формируя свою социальную базу среди тех, кто действительно в силу своей социальной слабости опасается рынка. Почему Республиканская партия России (РПР) объявила свою приверженность к блоку демократических сил, находящихся в оппозиции к КПСС? Потому, что мы видим различия, прежде всего, в механизмах социально-экономической политики. В программных документах РПР утверждается: основа экономики - предприниматель. Поэтому свою опору, социальную базу партия видит, прежде всего, в тех членах нашего общества, которые способны на инициативу, на смелые, неординарные шаги. Кому не известны горькие принципы 70-х гг.: “Не высовывайся! Инициатива - наказуема!”. Но предпринимателя, менеджера надо еще вырастить». Затем Борис Кимович заявил о том, что в местных советах Томска образована депутатская группа «Демократический Томск», входящая в движение «Демократическая России» [Там же. Л. 4].

Несмотря на различия во времени появления региональных организаций «Демократической России», они были созданы во всех крупных городах Западной Сибири. Это свидетельствует о том, что политические процессы в регионе развивались параллельно общероссийским. Помимо «Демократической России» и партий, в нее входящих, на территории Западной Сибири действовали политические организации, по той или иной причине в «Демократическую Россию» не вошедшие. Так, по данным газеты «Красное знамя», в 1991 г. в Томске развернули деятельность «Женская партия», 23 февраля в городе прошло учредительное собрание Партии свободного труда [5. С. 90].

Координационный совет Томского отделения движения «Демократическая Россия» в газете «Народная трибуна» последовательно отстаивает политику реформ Президента РСФСР Б.Н. Ельцина: «Президент РСФСР назначил своим представителем в области лидера демократических сил народного депутата СССР С. Сулакшина. Конференция Томского отделения движения “Демократическая Россия” рекомендовала главе администрации В.М. Крессу назначить на посты, связанные с основными направлениями реформы, прогрессивно настроенных специалистов, участников движения: Бауэра В.А., Вьюгова Б.И., Шайдуллина Б.К. и др. Однако действия В.М. Кресса по формировнаию администрации показали, что под ширмой разговоров о профессионализме реализуется прежний партийно-номенклатурный подход... Уж не будут ли проводить реформы те, кто жизнь посвятил последовательной и настойчивой борьбе с ними?» [6. Л. 7].

Анализ заявления показывает, что некоторые новые демократические силы региона активно поддерживали Президента РСФСР, но были настроены против губернатора Томской области. Однако на Томской земле имелись объединения, оппозиционно настроенные по отношению к любой власти. Например, в первом номере информационного листка (букв. «информлистка») 
«Рабочий», созданном анархо-синдикалистами г. Томска-7 под лозунгом «Освобождение рабочих - дело рук самих рабочих», коллектив редакции обосновал выход данного издания «необходимостью довести до сведения рабочих ту информацию, которую не увидишь на страницах демократических и прокоммунистических газет». Редакторы отметили далее: «В информлисте, в различных его рубриках, можно ознакомиться с материалами о рабочем движении нашей страны, об опыте работы зарубежных, рабочих организаций и другой, полезной для простого трудяги информацией. Мы надеемся, что информлисток "Рабочий” хоть как-то поможет вам сориентироваться в условиях надвигающегося, дикого, капиталистического рынка». Также в номере содержится пояснение редакторов самой сути синдикализма - «это идеология организованных трудящихся, не желающих мириться с положением наемных работников у государства или капиталиста, терпеть их произвол и самодурство, а также желающих стать хозяевами своего предприятия, на котором работают» [7. Л. 76].

Несколько позже Игорь Кузнецов, местный политолог, в статье «Синдикалистские профсоюзы в Сибири» подробно разъяснил читателям истоки синдикалистского движения в Томской области: «В 1989 г. в Москве прошел I съезд Конфедерации анархо-синдикалистов (КАС). Через год создали свое объединение анархосиндикалисты Сибири. До 1992 г. они сотрудничали с СОЦПРОФ, шахтерским движением. С 1992 г. начали создавать собственные профсоюзы (синдикаты). Отличие их от обычных профсоюзов в том, что конечная цель синдикатов - переход средств производства в руки трудящихся, создание самоуправления “снизу вверх", упраздняющее государство. Так как до этого далеко, то сегодняшнее отличие синдиката от тред-юниона еще и в том, что отсутствуют президенты, председатели и “боссы”, все вопросы решаются путем опроса, референдума или путем консенсуса. Если согласие невозможно, то меньшинство не подчиняется большинству, но и не противодействует ему. В 1992 г. подобные организации в рамках ФНПР начали создаваться в г. Северске Томской области. В 1993 г. - в Омской области, где действует уже ОКТ - Омская конфедерация труда. Активисты синдикалистских профсоюзов Северска помогают всем вне зависимости от членства в профсоюзе», - подчеркнул И. Кузнецов [8. Л. 47].

Следует заметить, что классические профсоюзы Томска тоже выражали неодобрение политики главе государства. Тому свидетельство открытое письмо президенту РФ на первой полосе профсоюзной газеты «Действие», в котором рабочие выразили основную претензию: «Очередное подорожание всех без исключения продуктов питания и товаров первой необходимости!» и требование в лозунге - «Хлеб должен быть доступен народу» [9. Л. 4].

В июле 1993 г. томская газета «Красное знамя» опубликовала статью «Общество прозревает и левеет», где выдвигалась принятая IV Пленумом Томского областного исполкома Коммунистической партии Российской Федерации (КПРФ) программа, включающая в себя: сохранение советской власти; проведение приватизации через трудовые коллективы; сохранение государственной собственности в базовых отраслях; восстановление монополии внешней торговли; разумная налоговая политика; денежная реформа; возвращение к «народному контролю за распределением»; цивилизованное отношение к науке, культуре, здравоохранению; объединение республик на новой основе. Эту программу коммунисты Томской области решили вынести на обсуждение облсовета. С ней КПРФ планировала одержать победу на выборах народных депутатов и глав администраций [5. С. 57].

Б.К. Шайдуллин, руководитель регионального отделения объединения «Яблоко», в своей статье «Томскому вестнику» охарактеризовал 1993 г. как время «Политического застоя в области»: «Партии, именующиеся демократическими, себя почти не проявляют. Нет реальной широкой коалиции. Куда девался "Выбор России”? Где “Экологическая инициатива"? Где ТНД, РПРФ и другие? Что это? Проявление осторожности? А может быть, куплены подачками? Судя по неучастию кандидата от коммунистов в выборах губернатора, эта власть устраивает и их. У нас в Томске в условиях отсутствия широкой оппозиции сформировалась монополия власти. Считаю, что в Томске только объединение “Яблоко" действует организованно и последовательно. Думаю, что застой, желание сохраниться во власти - вот главные мотивы, которыми руководствуется губернатор области. Сейчас готовимся к конгрессу демократической коалиции. Возможно, в нем примет участие и Г. Явлинский. Главное, что нас объединяет, - это глубокая неудовлетворенность состоянием общества» [10. Л. 8].

Два года спустя выйдет в свет нулевой номер газеты «ЭПИ-Центр», что означало, по словам инициаторов его создания, «закрепление в г. Томске еще одного звена гражданского общества, которое имело естественную потребность общаться с людьми, вести расширение круга единомышленников». Члены объединения «ЭПИ-центр» считали себя оппозицией власти, «которая сумела по существу сохранить прошлое партийнономенклатурное содержание, сбросив при этом лишь маску лицемерно-коммунистической идеологии». Девиз сообщества - «Информация - Закон - Разум - Демократия». Интерес вызывает фотография титульного листа издания, на котором Б.К. Шайдуллин и Г.А. Явлинский обмениваются дружелюбным рукопожатием [11. Л. 6].

Не случайно, по данным газеты «Красное знамя» 1995 г., наиболее мощным объединением «Яблока» в Западной Сибири стала организация Томска, где лидеры надеялись на победу в ходе предстоящих думских выборов [12. С. 80]. 
В 1995 г. в прессе появилась информация о создании еще одного регионального отделения политической силы демократического толка. В марте 1995 г. в Томске открылся офис Либерально-демократической партии России (ЛДПР). Члены ЛДПР начали работу по распространению Устава и программы партии, думского отчета фракции ЛДПР и обращения В. Жириновского к сотрудникам спецслужб [12. С. 76].

Коммунисты Томской области в исследуемый период также активно отстаивали свою позицию, а точнее оппозицию, в информационном пространстве региона. Так, в газете «Коммунист» в 1996 г. было размещено обращение участников конференции Томского регионального отделения НПСР: «Дорогие земляки! В Томске создано региональное отделение народнопатриотических сил России. Его учредителем выступили областные организации Коммунистической партии РФ, Российской коммунистической рабочей партии, Российского коммунистического союза молодежи, Аграрной партии России, общественное движение "Инициатива". Главная задача нового общественного движения - всемерно противостоять антинародному Правительству и его структурам в центре и на местах, приведших нашу страну к глубочайшему кризису. 3 июля большинство томичей, поддавшись лживой пропаганде, проголосовали за Б. Ельцина, дальнейшее продолжение курса антинародных реформ. Многие поверили тогда его заверениям сделать Россию процветающей страной. Прошли выборы и развеялась эйфория надежд на хорошего царя-батюшку. Уважаемые томичи! 22 декабря в Томске и области пройдут выборы в представительные органы местного самоуправления. Патриоты Томской области выдвигают для работы в них проверенных, деловых, компетентных и честных людей. Мы обращаемся к вам с просьбой сделать мудрый и осознанный выбор» [13. Л. 1].

Издание Томского областного комитета Российского коммунистического союза молодежи «Молодая гвардия» тоже обращается к населению области со своими призывами: «Нынче время - смуты и хаоса в общественно-политической жизни, исторический провал в никуда, за который потомки будут со стыдом вспоминать нас, и задвинут наше время в самый дальний и маленький параграф учебника истории XXI века. 7 ноября в колонне антирежимной оппозиции впереди прошла наша небольшая шеренга. Многочисленные тележурналисты и борзописцы местных газет на этот раз сильно делали вид, что они владеют навыками элементарной демократии, но все-таки не решились официально показать существование в Томске комсомольской организации. А ведь зря. Потеряют из виду» [14. Л. 1].

И вот как молодые коммунисты прокомментировали избирательную кампанию 1995 г.: «С наступлением зимы целые косяки политиков жадно табунились вокруг «Томского вестника» - наиболее известной и якобы демократической газеты. Дело понятное. Кто ставит на “ТВ”, тот садится в кресло. “Томский вестник” сам не простак, политическую конъюнктуру тоже отслеживал, принимал политических сватов, ломал руки и думал: “На кого же поставить?” - на элдэпээрчиков, так те ребята не солидные, зашорились на своем Жириновском так, что все заборы в Томске покрыли “наскальной живописью" - примитивно. Поставить на демократов, - да не хочется очередного конфуза; на коммунистов - страшно, ведь опять под них перевертываться придется. В конечном счете, опять пришлось рекламировать старых заезженных демократических кляч типа Сулакшина и Бауэра. Более тридцати процентов российских избирателей отдали предпочтение коммунистам. Тем не менее, в одномандатном Томском округе, выборы выиграл, введя в шоковое состояние почти весь город, четырехкратный депутат - Степан Сулакшин. Интересная эволюция этого героя изобилует самыми разнообразными политическими выкрутасами (сначала он «коммунист», затем демократизатор, потом оголтелый демократ - обиженный демократ и т.д.). А, в конечном счете, нас забавляет два интереснейших следствия прошедших выборов: во-первых, высокая избирательная активность и это очень хорошо - народ просыпается; во-вторых, с этого момента наконец-то всем станет ясно, что Жириновский, Явлинский, Черномырдин и прочие якобы «несовместимые» демократы это все одно лицо. В предстоящей Думе, в противовес фракции коммунистов, все они дружно будут работать на образование одной фракции - радикалдемократов пещерного капитализма. Будут “спасать” демократию, а на деле, еще больше усугублять политический кризис власти» [Там же. Л. 2].

В предвыборную президентскую кампанию 1996 г. активную агитацию за Президента Б.Н. Ельцина проводили на страницах томской прессы, где в его поддержку помимо ряда политических партий высказался президент «Восточной нефтяной компании» Л. Филимонов, ставший доверенным лицом Б.Н. Ельцина. Газета «Томский вестник» от 21 мая убеждала избирателей, что Б.Н. Ельцин создаст коалиционное правительство. На страницах той же газеты велась критика Г. Зюганова, А. Лебедя, Г. Явлинского, Св. Федорова. 28 июня в Томск прибыла большая группа депутатов от НДР во главе с Беляевым, возложившим вину за невыплату зарплат на местные власти. Своеобразным апофеозом агитации за действующего Президента стал круглый стол под названием «Что день грядущий нам готовит?». Мероприятие проводилось Антифашистским комитетом, а присутствовали на нем Л. Уханов - проректор Высшего экономикоюридического колледжа, Н. Корпицкий - «Антифашистское молодежное действие», А. Сологаев - профессор Томского педагогического университета, Б. Шайдуллин - «Яблоко», С. Чистяков - предприниматель, сопредседатель коалиции «Достаток, порядок, справедливость», М. Райдман - директор АО «Реатон», Н. Кречетова - глава департамента обладминистрации. 
Как следствие, публикация материалов круглого стола стала очередной агитационной акцией в поддержку Б.Н. Ельцина. В течение мая-июня газета публиковала интерпретацию на указы Б. Ельцина, касающиеся проблем ветеранов, свободы слова и прессы, государственной поддержки экономического и социального развития Сибири. В итоге результаты первого тура выборов оказались удовлетворительными. В Томской области кандидатура Б.Н. Ельцина набрала 35,07\% голосов, оставив позади Г. Зюганова и А. Лебедя, получивших 21,97 и 19,70\% соответственно [12. С. 114].

А в 1997 г. еще одно томское коммунистическое издание - газета «Искра» - так комментировало события в стране: «Общий кризис правящей олигархии Ельцина-Черномырдина продолжает углубляться. Кризис в промышленности и энергетике перерастает в кризис финансов и социальной сферы. Неуклонно растет долг по выплате зарплат и пенсий, ширятся забастовки шахтеров и энергетиков, рабочих заводов и служащих бюджетной сферы. Есть ли общественно-политические силы, которые могли бы в короткий срок вернуть жизнь людей в нормальное русло? Да, такие силы есть - это современные коммунисты. Но пока коммунисты разделены на множество партий, нет и не будет у них авторитета в массах» [15. Л. 1].

Однако, несмотря на веру в самих себя, Томская организация КПРФ по различным данным насчитывала 1500-2000 членов и являлась одной из самых слабых в западносибирском регионе. На декабрьских выборах 1997 г. коммунистам удалось провести в областную думу только 2 из 27 выдвинутых кандидатов [12. С. 122].

В целом, позиции основных региональных печатных СМИ Томской области в исследуемый период были представлены следующим образом:

1. Газета «Красное знамя» придерживалась центристских позиций, ближе к левым, отражала в большей мере интересы бывших руководителей промышленных государственных предприятий, демократические силы сотрудничали с газетой. Здесь были попытки анализа экономической реформы. Бывшая обкомовская. Издавалась на средства учредителей и на доходы от рекламы.

2. Газета «Томский вестник» придерживалась правоцентристских позиций, поддерживалась демократическими организациями, депутатами. Учредителем был горсовет Томска. Издавалась на средства из городского бюджета и средства подписчиков.

3. Газета «Народная трибуна» - левого толка, предоставляла страницы всем политическим силам без разбора. Учреждена облсоветом. Поддерживала позицию облсовета, критиковала президента, правительство. Издавалась на средства подписчиков, облсовета и рекламы [16. Л. 3].

Выборочный анализ публикаций Томских печатных СМИ 1990-1997 гг. позволил автору сделать выводы о том, что местные издания:

- в 1990-1992 гг. особенно остро сопереживали с читателями неудачи экономических реформ и винили во всем КПСС;

- с 1990 по 1995 г. активно печатали материалы о вновь образующихся движениях и партиях, зачастую разделяя демократические позиции;

- с 1995 по 1997 г. начинают критиковать демократические силы;

- активизировались накануне предвыборных кампаний;

- представляли интересы лояльных руководству страны и области политических сил, оппозиционно настроенных организаций, а также независимых взглядов и мнений;

- вывели в свет новых политических деятелей, таких как С. Сулакшин и Б. Шайдуллин, а также публиковали материалы об уже известных читателям персонах, таких как В. Кресс;

- в исследуемый период выявили и рассмотрели на своих страницах большой спектр социальнополитических и экономических проблем в стране и Томской области.

\section{ЛИТЕРАТУРА}

1. Центр документации новейшей истории Томской области (ЦДНИИ ТО). Ф. Газеты. Д. 352. Л. 1. Народная воля (Томск). 1990. № 2.

2. ЦДНИИ ТО. Ф. Газеты. Д. 353. Л 12. Народная трибуна (Томск). 1990. 24 мая. № 1.

3. ЦДНИИ ТО. Ф. 5654. Оп 1. Д. 114. Л. 102. Письма читателей газеты «Народная трибуна».

4. ЦДНИИ ТО. Ф. Газеты. Д. 390. Л. 3-4. Республика (Томск). 1990. Ноя.

5. Новиков С.В. Политические партии, общественно-политические движения, пресса, избиратель Западной Сибири: проблемы взаимовлияния. 1988-1996 гг. Омск : Изд-во ОмГАУ, 2002. 408 с.

6. ЦДНИИ ТО. Ф. 5642. Оп. 1. Д. 31. Л. 7. Народная трибуна (Томск). 1991. 29 ноя.

7. ЦДНИИ ТО. Ф. 5643. Оп. 1. Д. 79. Л. 76. Рабочий (Томск). 1992. Апрель. № 1.

8. ЦДНИИ ТО. Ф. 5643. Оп. 1. Д. 108. Л. 47. Народная трибуна (Томск). 1994. 17 ноя. № 227-228.

9. ЦДНИИ ТО. Ф. Газеты. Д. 586. Л. 4. Действие (Томск). 1992. 7 окт. № 34 (72).

10. ЦДНИИ ТО. Ф. 5642. Оп. 1. Д. 32. Л. 8. Томский вестник (Томск). 1993. 3 мая. № 82.

11. ЦДНИИ ТО. Ф. 5691. Оп. 1. Д. 65. Л. 6. ЭПИцентр (Томск). 1995. Декабрь. № 0

12. Новиков В.С. Региональные отделения политических партий и печатные СМИ в процессе формирования предпочтений избирателя. 19922000 гг. На материалах Западной Сибири / В.С. Новиков, С.В. Новиков. Омск : ИПК Макшеевой Е.А., 2011.200 с.

13. ЦДНИИ ТО. Ф. Газеты. Д. 820. Л. 1. Коммунист (Томск). 1996. Ноябрь. № 13.

14. ЦДНИИ ТО. Ф. Газеты. Д. 829. Л. 1-2. Молодая гвардия (Томск). 1996. Январь. № 1.

15. ЦДНИИ ТО. Ф. Газеты. Д. 862. Л. 1. Искра (Томск). 1997. Май. № 1.

16. ЦДНИИ ТО. Ф. 5654. Оп. 1. Д. 296. Л. 3. Аналитический обзор Томского отделения коалиции «Солидарность и реформы о политической позиции региональных СМИ Томской области». 


\section{Bobkova Natalya P. Omsk State Agrarian University (Omsk, Russian Federation). E-mail: volodina_84_84@mail.ru} A SPECTRUM OF THE DISCUSSED POLITICAL TOPICS IN THE PUBLICATIONS OF THE TOMSK REGION IN 19901997.

Keywords: printed editions; political publications; political parties and policy makers; political positions.

The first years of economic (market) reforms, first held in the USSR and then in Russia, were accompanied by a sharp decline in living standards of the population and a deep administrative and political crisis. All these phenomenon and processes were relevant to the editorial boards of both central and regional press. In view of the extensiveness of the published on the pages in the print media material of those years, it is reasonable to analyze it comprehensively and regional. The aim of this study is to highlight some of the political problems of the early 1990's on the basis of the print media of the Tomsk region. The topicality of the research is determined by the increasing role of opposition political propaganda and demonstration of interest in the study of problems in historical aspect. The subject of this work is political issues on the pages of printed media of the Tomsk region in 1990-1997. The main methods of the research are the principle of historicism and content analysis of the press. The result of the work was the analysis of regional printed media. The last one allowed to the author to draw conclusion that these regional printed media reflected the political situation in the country and in the region, had their own perspective on the events of that time. In general, the positions of the main regional print media of the Tomsk region during the researched period were as follows: - The newspaper «Krasnoye Znamya» («The Red flag»), the followers of the centrist positions, closer to the left, reflects mostly the interests of former heads of state industrial enterprises; the democratic forces cooperated with this newspaper. There have been attempts to analyze economic reforms. It is the former newspaper of the Regional Committee of the CPSU. It was published at the expense of founders and advertising revenues. - The newspaper «Tomskiy Vestnik» («The Bulletin of Tomsk») is centre-right, and is supported by democratic organizations, deputies. The founder of the newspaper is the Council of the city of Tomsk. The newspaper is published with funds from the city budget and the funds of subscribers. - The newspaper «Narodnaya tribuna» («The tribune of the people») is the left position, provides a page with all political forces indiscriminately. The newspaper is established by the Regional Council and supports the position of the regional Council, criticizes the President and the Government. This periodical is published with funds from the Regional Council, subscribers and advertising. After sample analysis of publications of Tomsk print media in 1990-1997, the author concludes that local periodical print publications: - In 1990-1992 - they particularly acute empathy with readers of the failure of economic reforms and blamed all of the CPSU; - From 1990 to 1995 - they actively printed materials about the newly formed parties and movements, often dividing the democratic position; - From 1995 to 1997 - they start to criticize the democratic forces; - They intensified on the eve of election campaigns; - They represented the interests loyal to the government and political forces, opposition organizations, as well as independent views and opinions; - They brought in the light of new policy makers such as S. Sulakshin, and B. Shaydullin, as well as published materials about the persons already known to the readers, such as B. Kress; - In the period under review they had identified and reviewed on their page a wide range of socio-political and economic problems in the country and the region.

\section{REFERENCES}

1. Narodnaya volya. (1990) The Centre for Documentation of Contemporary History of Tomsk Region (TsDNII TO). Fund Newspapers. File 352. Page 1. (Tomsk). 2. (In Russian).

2. Narodnaya tribuna. (1990) The Centre for Documentation of Contemporary History of Tomsk Region (TsDNII TO). Fund Newspapers. File 353. Page 12. Tomsk, 24th May.

3. Pis'ma chitateley gazety "Narodnaya tribuna" [Letters from readers of the newspaper Narodnaya tribuna]. The Centre for Documentation of Contemporary History of Tomsk Region (TsDNII TO). Fund 5654. List 1. File 114. Page 102. Tomsk. (In Russian).

4. Respublika. (1990) The Centre for Documentation of Contemporary History of Tomsk Region (TsDNII TO). Fund Newspapers. File 390. P. 3-4. Tomsk. November. (In Russian).

5. Novikov, S.V. (2002) Politicheskie partii, obshchestvenno-politicheskie dvizheniya, pressa, izbiratel' Zapadnoy Sibiri: problemy vzaimovliyaniya. 1988-1996 gg. [Political parties, socio-political movement, mass media, elector of Western Siberia: the problem of mutual interaction. 1988-1996]. Omsk: Omsk State Agrarian University.

6. Narodnaya tribuna. (1991) The Centre for Documentation of Contemporary History of Tomsk Region (TsDNII TO). Fund 5642. List 1. File 31. P. 7. Tomsk. 29th November. (In Russian).

7. Rabochiy. (1992) The Centre for Documentation of Contemporary History of Tomsk Region (TsDNII TO). Fund 5643. List 1. File 79. P. 76. Tomsk. 1st April. (In Russian).

8. Narodnaya tribuna. (1994) The Centre for Documentation of Contemporary History of Tomsk Region (TsDNII TO). Fund 5643. List 1. File 108. P. 47. Tomsk. 17th November. (In Russian).

9. Deystvie. (1992) The Centre for Documentation of Contemporary History of Tomsk Region (TsDNII TO). Fund Newspapers. File 586. P. 4. Tomsk. 7 th October. (In Russian).

10. Tomskiy vestnik. (1993) The Centre for Documentation of Contemporary History of Tomsk Region (TsDNII TO). Fund 5642. List 1. File 32 . P. 8. Tomsk. 3th May. (In Russian).

11. EPItsentr. (1995) The Centre for Documentation of Contemporary History of Tomsk Region (TsDNII TO). Fund 5691. List 1. File 65. P. 6. Tomsk. December. (In Russian).

12. Novikov, V.S. \& Novikov, S.V. (2011) Regional'nye otdeleniya politicheskikh partiy i pechatnye SMI v protsesse formirovaniya predpochteniy izbiratelya. 1992-2000 gg. Na materialakh Zapadnoy Sibiri [The regional offices of political parties and the print media in formation of voter preferences. Western Siberia, 1992-2000]. Omsk: IPK Maksheevoy E.A.

13. Kommunist. (1996) The Centre for Documentation of Contemporary History of Tomsk Region (TsDNII TO). Fund Newspapers. File 820. P. 1. Tomsk. November. (In Russian).

14. Molodaya gvardiya. (1996) The Centre for Documentation of Contemporary History of Tomsk Region (TsDNII TO). Fund Newspapers. File 829. P. 1-2. Tomsk. January. (In Russian).

15. Iskra. (1997) The Centre for Documentation of Contemporary History of Tomsk Region (TsDNII TO). Fund Newspapers. File 862. P. 1. Tomsk. May. (In Russian).

16. The Centre for Documentation of Contemporary History of Tomsk Region (TsDNII TO). Fund 5654. List 1. File 296. P. 3. (In Russian). 